\title{
Validation of an Instrument to Assess Beliefs About Nature of Science and Scientific Inquiry in Namibia
}

\author{
Simson Ndadaleka Shaakumeni \\ Doctoral School of Education, University of Szeged, Hungary
}

Doi: 10.19044/ejes.v6no2a2

URL:http://dx.doi.org/10.19044/ejes.v6no2a2

\begin{abstract}
The aim of this study was to validate a new 5-point Likert scale questionnaire that is being developed to assess secondary school science students' beliefs about the nature of scientific knowledge and scientific inquiry. Following a review of literature, it was found that out of the many existing instruments, most of them were open-ended and none were found to have been developed in the cultural context of Namibia. The beliefs about nature of science (BANOS) questionnaire is currently being developed to break the ground for future cross-sectional research on the nature of science and scientific inquiry in Namibia. The BANOS questionnaire taps from aspects of nature of science and scientific inquiry as a theoretical framework. The 35-item BANOS questionnaire was administered to a sample of 124 (39\% male and $61 \%$ female) secondary school science teachers. The analysis of the instrument showed that the average inter-item correlation was reasonable at $r$ $=.40$, the mean item-total correlations were acceptable at $r=.63$ and the reliability was very high at $\alpha=.96$. Science teachers response pattern showed several variations indicating mixed beliefs about the nature of science and scientific inquiry. At non-parametric level, it was established that gender, science teaching and the type of science subject taught did not influence teachers' beliefs about nature of science and scientific inquiry. Further piloting of the questionnaire on adequate sample of student population is needed to enable more robust statistical analyses to assess the psychometric properties of the instrument.
\end{abstract}

Keywords: Nature of science; beliefs; validity/reliability, scientific inquiry.

\section{Introduction}

The National Curriculum for Basic Education (NCBE) in Namibia, which is the broad curriculum, demands that students should develop into scientific literate citizens (Ministry of Education, 2010). According to the $\mathrm{NCBE}$, one of the components of scientific literacy is the understanding of the 
nature of scientific knowledge. The nature of science entails what makes science different from other disciplines. In other words, it characterises scientific knowledge that is derived from how the knowledge is developed (Lederman, et al., 2014). However, the assessment of science knowledge in Namibian schools does not include these aspects of scientific literacy. All assessments mainly focus on the subject content knowledge. They hardly include assessing students' abilities to carry out inquiry and whether they acquire fundamental understanding of the characteristics of nature of science and scientific inquiry. One way to ascertain students' understanding of the nature of scientific knowledge and knowing is to assess their science epistemic beliefs. Advancing students' beliefs about the nature of scientific knowledge and knowing has featured prominently in recent research in science education (Conley, Pintrich, Vekiri, \& Harrison, 2004; Tsai, Ho, Liang, \& Lin, 2011; Chen, 2012; Chen, Metcalf, \& Tutwiler, 2014). However, none of such studies appear to have been conducted in Namibia.

\section{Theoretical Background}

\section{Nature of Science}

One important goal of science education is to foster students' scientific literacy (Nowak, Tiemann, \& Upmeier zu Belzen, 2013; Peters-Burton, 2016). Scientific literacy consists of different components, namely; content knowledge, nature of science, and scientific inquiry. The concept nature of science has been commonly used to refer to "the epistemology of science; science as a way of knowing or the values and beliefs inherent to the development of scientific knowledge" (Lederman, 1992, p. 331; 2007). This definition of nature of science is rather general and till date, there is still disagreement among philosophers of science, historians of science, scientists, and science educators on the specific definition of the concept (Abd-ElKhalick, 1998)

Students should develop certain habits of the mind such as believing that scientific knowledge (1) can change over time (tentative), (2) empiricallybased (based on and/or derived from observations of the natural world), (3) there is no one way of doing science called "the Scientific Method", (4) subjective (theory-laden) - partially based on human inference, (5) influenced by imagination and creativity, (6) socially and culturally embedded, (7) observation and inference are different, and (8) theories and laws are distinct kinds of scientific knowledge (Abd-El-Khalick \& Lederman, 2000; Lederman, 2007; McComas, 2008; Osborne, Collins, Ratcliffe, \& Duschl, 2003; Niaz, 2009; Chen, 2012; Abd-El-Khalick, et al., 2017). 


\section{Scientific Inquiry}

Scientific inquiry as a component of scientific literacy has been defined in various ways. Schmidt, Smyth, and Kowalski (2014) defined scientific inquiry as "a powerful way of understanding science content. Students learn how to ask questions and use evidence to answer them. In the process of learning the strategies of scientific inquiry, students learn to conduct an investigation and collect evidence from a variety of sources, develop an explanation from the data and communicate and defend their conclusions" (p. 4).

According to Lederman et al. (2014), scientific inquiry refers to "the combination of general science process skills with traditional science content, creativity, and critical thinking to develop scientific knowledge" (p. 65). The aspects of scientific inquiry that students in secondary level should be able to understand and articulate is that: (1) all scientific investigations begin with a question but do not necessarily test a hypothesis, (2) there is no single set or sequence of steps followed in all investigations, (3) inquiry procedures are guided by the question(s) asked, (4) all scientists performing the same procedures may not get the same results, (5) inquiry procedures can influence results, (6) research conclusions must be consistent with the data collected, (7) scientific data are not the same as scientific evidence, and (8) explanations are developed from a combination of collected data and what is already known (Lederman et al., 2017).

Scientific inquiry, though closely related, is not necessarily a component of nature of science. It refers to how scientists carry out their work and how the resultant knowledge is generated and accepted. Moreover, nature of science constitutes what makes science different from other disciplines such as Sociology or History. Hence, it refers to the characteristics of scientific knowledge that are necessarily derived from how the knowledge is developed (Lederman et al., 2014). Developing a tool for assessing beliefs about the preceding aspects that characterise the nature of science and scientific inquiry is the focus of this study.

\section{Assessing Beliefs about Nature of Science}

Numerous instruments for assessing beliefs about the nature of science exist (Lederman, Wade, \& Bell, 1998; Summers \& Abd-El-Khalick, 2017). However, none were found to have been developed in the cultural context of Namibia. Moreover, the widely-used instrument in this area of research in recent years is the Views of the Nature of Science (VNOS) questionnaire developed by Lederman, Abd-El-Khalick, Bell, and Schwartz (2002).

The VNOS is an open-ended questionnaire and items that often do not directly specify the targeted aspects of nature of science. Subsequently, it becomes too optimistic to assume that participants would be able to adequately 
articulate the details sought within a limited time frame. Thus, it becomes difficult for a researcher to obtain the intended information from every participant without follow-up interviews (Chen, 2006). Although Lederman et al. (2002) advised that a large proportion of respondents should be interviewed after taking the questionnaire to validate responses, this has not been ideal for this study at the moment due to limited access to state schools in Namibia.

Another argument against the use of open-ended questionnaire to gather views is that it requires a substantial commitment of time and mental grit from each participant to articulate their views (Osborne, Collins, Ratcliffe, Millar \& Duschl, 2003). As a result, only few respondents may endeavour to articulate their views. This renders open-ended questionnaires inappropriate for large scale empirical studies, attributable to the smaller samples involved as well as limited possibilities of applying statistical analysis to qualitative data. The forgoing arguments form the basis to justify the choice of the type of instrument being developed in this study.

\section{Research Aims and Objectives}

The aim of this study is to validate a new instrument that was developed to assess secondary school science students' beliefs about the nature of scientific knowledge and scientific inquiry in Namibia. Hence, this paper reports on the first pilot study that was carried out in Namibia using a sample of science teachers as one of the preliminary steps in the validation process. The following questions were answered:

1. How do items function in the instrument?

2. What is the reliability of the instrument?

3. What are the science teachers' overall beliefs about nature of science and scientific inquiry?

4. Is there any difference in beliefs among teachers based on gender, teaching experience or type of science subject taught?

\section{Methods}

Participants

It should be noted that the questionnaire was developed to assess students' beliefs about nature of science and scientific inquiry. However, as part of the preliminary stages of the validation process, the questionnaire was administered to a sample of 124 (39\% male and 61\% female) science teachers in three regions in Namibia. The criterion for inclusion was that teachers must have been teaching either of the two science subjects that make up the Natural Sciences in the Namibian curriculum. This means they should either be teaching Biology or Physical Science at secondary level. The respondents were grouped into ranges of years of experience in science teaching from 0-3 years to over 10 years. 


\section{Instrument Development}

The theoretical framework for the development of the instrument for assessing beliefs about the nature of science is based on the general and symbiotic aspects of nature of science and scientific inquiry as proposed by Lederman and other scholars (Lederman, Abd-El-Khalick, Bell, \& Schwartz, 2002; Lederman \& Abd-El-Khalick, 1998; McComas, Almazroa, \& Clough, 1998, Lederman et al.,2014). These aspects of nature of science, though criticised by some science educators as being too general, over-simplified, prescriptive and narrow (Irzik \& Nola, 2011; Mathews, 2012; Dagher \& Erduran, 2016; Grandy \& Duschl, 2008), they are considered to be a useful guiding framework for this study. This framework was adopted based on the clarification provided by proponents of the general aspects of nature of science, who in response to criticisms stated that the suggested general aspects of nature of science and scientific inquiry are by no means "a definitive or universal definition of the construct" (Lederman, Antink, \& Bartos, 2014, p. 286).

In the present study, a new questionnaire termed "Beliefs about Nature of Science" (BANOS) has been developed. However, ideas for possible items were obtained from existing scales in the literature. The first version of the BANOS questionnaire comprised of thirty-five items. The items were declarative statements describing particular aspects of nature of scientific knowledge including scientific inquiry. Respondents gave their personal level of belief or agreement with the five-point Likert scale (Cohen, Manion, \& Morrison, 2007), namely; $1=$ strongly disagree, $2=$ disagree, $3=$ not sure, 4 $=$ agree , and $5=$ strongly agree .

The declarative statements are organised according to the general aspects of nature of science and scientific inquiry. All statements were in a form of sophisticated/informed views of respondents about nature of science and scientific inquiry obtained from the literature (Vhurumuku, 2010; Dogan \& Abd-El-Khalick, 2008; Chen, 2006; Khishfe \& Abd-El-Khalick, 2002; Summers \& Abd-El-Khalick, 2017). All statements were positively worded so that a high score indicate more sophisticated beliefs about the nature of science and scientific inquiry. The BANOS questionnaire maximum total raw score is 175 and a minimum of 35 .

\section{Procedure}

An assessment of validity and reliability was conducted on the questionnaire. To ascertain face and content validity, a review of over seventy recent researches on nature of science and scientific inquiry was done. This served to ensure the accuracy of each declarative statement (item) that was used in the questionnaire. To check for comprehension and readability, the paper-and-pencil questionnaire was administered to a sample of 124 science 
teachers that were purposefully sampled from three regions in Namibia. The involvement of teachers is also to some extent expected to provide some validation as teachers' beliefs are expected to be different from that of students.

An English language expert was also engaged to read through the statements and modifications made were applicable. The reliability of the instrument was demonstrated by confirming the internal consistency of the construct using Cronbach's alpha.

Ordinal scales were analysed as if they were interval scales (Glynn, Brickman, Armstrong \& Taasoobshirazi, 2011). In this case, items are assumed to be generally parallel indicators of the underlying latent variable (DeVellis, 2003).

\section{Results and Discussions}

\section{Inter-item Correlations}

In order to produce a reliable scale of measurement, it is imperative to analyse the extent to which responses on one item are related to responses on all other items in a scale. For this reason, inter-item correlations are an essential element in the initial analysis of a set of items.

This analysis provides information about the extent to which items on a scale are assessing the same construct (Cohen \& Swerdlik, 2005). The average inter-item correlation for a set of items should preferably be between $r=.20$ and $r=.40$ (Piedmont, 2014). This implies that although items should be reasonably similar in some way, it is pointless to have items on a scale that measure the construct in exactly the same way. When correlation values are below $r=.20$, it suggests that items do not relate to each other very well. Hence, it may not be suitable for measuring a single construct. Moreover, if the values are above $r=.40$, the items tend to be very similar to each other, almost to the point that they become redundant (Piedmont, 2014).

Table 1. Summary of item statistics

\begin{tabular}{lll}
\hline & Mean & No. of Items \\
\hline Item Means & 2.95 & 35 \\
Inter-Item Correlations & $\mathbf{. 4 0 3}$ & 35 \\
\hline
\end{tabular}

The average inter-item correlation for the items $(\mathrm{N}=35)$ in the first version of Beliefs about Nature of Science (BANOS) instrument was $r=.40$ (Table 1). As indicated above, correlations between $r=.20$ and $r=.40$ are preferable. This indicates that items are related to each other fairly well. Therefore, in the context of this study, they may be suitable for measuring beliefs about the nature of science and scientific inquiry in Namibia. 


\section{Item-total Correlations}

Items were further examined to ascertain whether there is an individual item whose score is not related to the summated score of all other items in the scale and such items are revised or discarded. This is essentially performing item-total correlations. Item-total correlation values between $r=.20$ and $r=$ .40 are desirable and a small correlation suggests that the item is not measuring the same construct measured by the other items in the scale (Field, 2005; Everitt, 2002). The mean item-total correlation $(\mathrm{N}=35)$ was $r=.63$. One item had correlation values less than $r=.20$. This shows that the item was not measuring the same construct measured by the other items in the instrument. This item was examined to ascertain whether it can be improved or be discarded. Three other items had correlations less than $r=.40$ but greater than $r=.20$. These items displayed very weak correlations and were reviewed. Since this is a validation process, the intention was not to discard items yet, but rather to modify them and pilot them for the second time. Subsequently, items were reviewed and none of the items were discarded based on these results.

\section{Reliability}

Reliability is a measure of how well the items in a scale measure the same construct over time (Streiner, 2003). This measure is commonly estimated using Cronbach's alpha reliability coefficient, which normally ranges between 0 and 1 . The closer Cronbach's alpha coefficient is to 1 , the greater the internal consistency of the items in the scale (Gliem \& Gliem, 2003). George and Mallery (2003) suggest that Cronbach's alpha of $\alpha=.70$ is acceptable. The Cronbach's alpha computed on all the 35 items $(\mathrm{N}=124)$ using SPSS version 23 was $\alpha=.96$. This shows that the instrument overall has very high reliability. Further assessment of reliability analysis reveals that there was no need to delete any item in order to improve the overall reliability value of the instrument.

The eight general aspects of nature of science and scientific inquiry made up the nine subscales in the instrument. Participants' responses on the items for each subscale were computed to determine the median (Elliot \& McGregor, 2001). Despite that the overall reliability of the instrument as a whole was very high, two subscales namely the empirical nature of scientific knowledge and the scientific method did not show very good reliability. The reliability of the two subscales were $\alpha=.51$ and $\alpha=.67$ respectively (Table 2). Deleting one item from the empirical subscale improved the alpha coefficient value slightly to $\alpha=.54$. However, this was still very low. Moreover, by deleting one item from the scientific method subscale improved the alpha coefficient to $\alpha=.73$. This alpha coefficient value is now reasonable, 
However, the items in this subscale were reviewed and will be piloted for the second time before any permanent dropping of the items is implemented.

Table 2. Reliability of the subscales

\begin{tabular}{lll}
\hline NOS aspects & No. of items & Cronbach's alpha $(\alpha)$ \\
\hline Tentative nature of science & 5 & .81 \\
Empirical nature of science & 4 & $.51(.54)^{*}$ \\
The scientific method & 3 & $.67(.73)^{*}$ \\
Subjective nature of science & 3 & .78 \\
Imaginative and Creativity & 4 & .75 \\
Socio-cultural influence & 3 & .88 \\
Observations and inferences & 3 & .90 \\
Theories \& laws & 5 & .83 \\
Scientific inquiry & 5 & .91 \\
Total items & 35 & .96 \\
\hline \multicolumn{2}{l}{}
\end{tabular}

The number of items in a scale partially influences the Cronbach's alpha values. These values could be increased by increasing the number of items in the scale or deleting individual items whose values are higher than the overall Cronbach's alpha value of the scale. The very high alpha values indicate that items were measuring the same construct very well. Notwithstanding the above, Gliem and Gliem (2003) cautioned that although a higher Cronbach's alpha indicates a good internal consistency of the items in the scale, it does not mean that the scale is uni-dimensional. Hence, factor analysis is still required to determine the dimensionality of the scale. However, for this first pilot study, factor analysis was not appropriate as the sample was inadequate to satisfy all the assumptions for factor analysis procedure. This will be done during the second pilot study.

\section{Subscale Correlations}

The intertwined aspects of nature of science and scientific inquiry formed subscales that reflect the core constructs of nature of science and scientific inquiry. When separate constructs are combined to form one scale, there is a need to justify that they are closely related (Summers \& Abd-ElKhalick, 2017). One way to show the relationship between constructs is by computing correlations. Without assuming causation (Carver \& Nash, 2012), the analysis showed that there was an overall significant positive relationship between subscales at $\mathrm{p}<.001$ (Table 3 ) level. The weakest correlation was between tentativeness and empirical subscales $(r=.27)$. The empirical nature of science subscale showed poor reliability values $(\alpha=.54$, Table 3$)$. Thus, this may explain this weak relationship. The strongest correlation was between observations and inferences and scientific inquiry $(r=.88)$. It should be noted that scientific inquiry though closely related, is not necessarily a component of nature of science because it entails the process of how scientists perform 
their work and how the resultant knowledge is generated and accepted (Lederman, et al., 2014). However, beliefs about it was considered important for this study.

Table 3. Subscales correlations

\begin{tabular}{|c|c|c|c|c|c|c|c|c|c|}
\hline Subscales & 1 & 2 & 3 & 4 & 5 & 6 & 7 & 8 & 9 \\
\hline $\begin{array}{l}\text { 1. Tentative nature of } \\
\text { science }\end{array}$ & - & & & & & & & & \\
\hline $\begin{array}{l}\text { 2. Empirical nature of } \\
\text { science }\end{array}$ & $.27^{* *}$ & - & & & & & & & \\
\hline 3. The scientific method & $.42^{* *}$ & $.51^{* *}$ & - & & & & & & \\
\hline $\begin{array}{l}\text { 4. Subjective nature of } \\
\text { science }\end{array}$ & $.59^{* *}$ & $.70^{* *}$ & $.50^{* *}$ & - & & & & & \\
\hline $\begin{array}{l}\text { 5. Imaginative and } \\
\text { creativity }\end{array}$ & $.44^{* *}$ & $.77^{* *}$ & $.56^{* *}$ & $.78^{* * *}$ & - & & & & \\
\hline 6. Sociocultural & $.38^{* *}$ & $.44^{* *}$ & $.43^{* *}$ & $.43^{* *}$ & $.57^{* *}$ & - & & & \\
\hline $\begin{array}{l}\text { 7. Observations and } \\
\text { inferences }\end{array}$ & $.64^{* *}$ & $.54^{* *}$ & $.56^{* *}$ & $.69^{* * *}$ & $.66^{* *}$ & $.66^{* *}$ & - & & \\
\hline 8. Theories and laws & $.53^{* *}$ & $.64^{* *}$ & $.71^{* *}$ & $.59^{* *}$ & $.69^{* *}$ & $.65^{* *}$ & $.77^{* *}$ & - & \\
\hline 9. Scientific inquiry & $.74^{* *}$ & $.55^{* *}$ & $.69^{* *}$ & $.70^{\text {*** }}$ & $.68^{* *}$ & $.53^{* *}$ & $.88^{* *}$ & $.86^{* *}$ & - \\
\hline
\end{tabular}

It should be noted, however, that very high significant correlations between subscales point to strong similarity. As indicated in preceding section, the overall Cronbach's alpha value was very high $(\alpha=.96)$ and most likely indicate unnecessary redundancy of items (and subsequently the subscales) rather than a desirable level of internal consistency (Streiner, 2003).

\section{Teachers' Response Patterns on Subscales}

Firstly, the median of responses was calculated for each subscale using the Statistical Package for Social Sciences (SPSS) version 23. The median as a measure of central tendency was deemed the most appropriate indicator of respondents' likeliest beliefs about each subscale. Secondly, the interquartile range (IQR) which is a measure of dispersion was also computed to indicate whether responses are clustered together or scattered across the range of possible responses. This is shown by the boxplot in Figure 1. With reference to the tentative nature of science, as shown in Figure 1, most respondents were more likely to choose option 4 (Agree) $(\mathrm{Mdn}=4, \mathrm{IQR}=3$ ). This aspect of nature of science is concerned with the idea that scientific knowledge is never absolute or certain but is subject to change (Abd-El-Khalick, et al., 2017; Lederman, 2007). However, the length of the boxplot indicates variability in opinion about this aspect of nature of science with more variability among the lower quartile. 


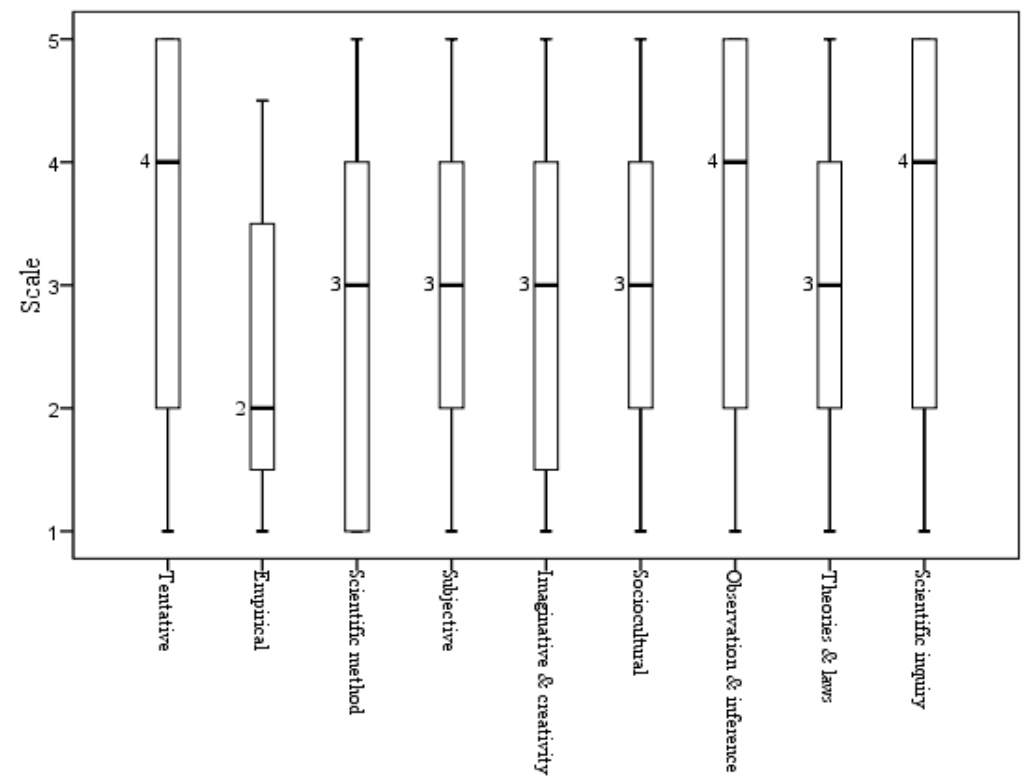

Figure 1. Boxplot of responses to subscales showing the median

Four items that made up the empirical nature of science subscale are: (1) science does not depend on experiments only to get evidence about the natural world, (2) experiments cannot prove a scientific theory true, (3) science cannot prove anything but is still valuable, and (4) scientific evidence can be obtained from observations of the natural world. Respondents indicated disagreement with this notion ( $\mathrm{Mdn}=2, \mathrm{IQR}=2$ ). As shown in Figure 1, most respondents were likely to choose option 2 (disagree). This indicates that teachers' beliefs about this aspect of nature of science were not accurate or they may have interpreted the items differently than expected. Experiments are useful tools in science but are not the only means to generate scientific knowledge (McComas, 1996). Scientific knowledge is also derived from the observation of the natural world (Lederman, 2007; Lederman, et al., 2014).

With regards to the scientific method, respondents appear to be unsure about this aspect of the nature of science $(\mathrm{Mdn}=3, \mathrm{IQR}=3)$. Respondents were most likely to choose option 3 (Not sure) and the variability of responses spread more within the lower quartile. This indicates that those who did not choose option 3 (Not sure) mostly disagreed or strongly disagreed. There is a commonly held misconception about science that there exists a single procedure which all scientists follow (Lederman, Abd-El-Khalick, Bell, \& Schwartz, 2002). This was inaccurate as there is no single scientific method that all scientists follow, but scientists use various methods in search of scientific knowledge (Abd-El-Khalick, Waters, \& Le, 2008; Abd-El-Khalick, et al., 2017). 
The work of scientists is influenced by their theoretical and disciplinary commitments, beliefs, prior work knowledge, training, and expectations (Abd-El-Khalick, et al., 2017). This suggests that scientific knowledge is subjective in nature as it is affected by scientists' backgrounds. Respondents' beliefs about this aspect of nature of science appear to be divided. About $48 \%$ of respondents disagreed but roughly equal proportion amounting to $45 \%$ of respondents indicated that they agreed $(\mathrm{Mdn}=3, \mathrm{IQR}=$ 2). This is also evident in Figure 1; the upper and lower quartiles appear roughly equal.

Respondents' beliefs about the imaginative and creative nature of science appear to show more uncertainty as well with more variability in the lower quartile ( $\mathrm{Mdn}=3, \mathrm{IQR}=2.5)$. Scientific knowledge production involves human creativity in terms of scientists inventing explanations and theoretical models, and this requires a great deal of creativity by scientists (Abd-ElKhalick, Waters, \& Le, 2008). Creativity and imagination are vital at all stages of a scientific endeavour; from planning and designing through data collection to data interpretation though with variable extent between stages (Wong \& Hodson, 2009).

Scientific knowledge affects and is affected by various cultural elements and spheres including social fabric, trends, prestige, power structures, religion, political and economic factors (McComas, 2008). Respondents' beliefs about this aspect of nature of science seem divided. About $32 \%$ of respondents agreed with this notion, but a sizeable proportion amounting to $32 \%$ of respondents disagreed $(\mathrm{Mdn}=3, \mathrm{IQR}=2)$.

With reference to the difference between observations and inferences, most respondents were again more likely to choose option 4 (Agree) $(\mathrm{Mdn}=$ 4 , IQR = 3). This aspect of nature of science deals with the fact that there is a crucial distinction between observations and inferences, although both are scientific processes skills. Observations are descriptions of the natural world that are accessible to the human senses whereby several observers could easily reach an agreement whilst inferences are interpretations or explanations of observations gathered (Lederman, Antink, \& Bartos, 2014; Schwartz, Lederman, \& Crawford, 2004). The response pattern in this subscale is also showing variability in responses about this aspect of nature of science with more variability visible in the lower quartile as evident in Figure 1.

About $35 \%$ of respondents disagreed with the notion that theories and laws are different, but a sizeable proportion amounting to $48 \%$ of respondents indicated that they agree $(\mathrm{Mdn}=3, \mathrm{IQR}=2)$. This is also evident in Figure 1; the upper and lower quartiles appear roughly similar. There are common misconceptions that there is a simplistic and hierarchical relationship between observations, hypotheses, theories and laws of science; and the belief that laws have a higher status than theories within a scientific endeavour (Lederman, 
Abd-El-Khalick, Bell, \& Schwartz, 2002). Theories and laws are related but are distinct kinds of scientific knowledge and for this reason they serve different roles in the scientific enterprise. Hence, theories do not in any way become laws, even with additional evidence (Niaz, 2009; McComas, 2008; Lederman, 2007).

Scientific inquiry, though closely related, is not necessarily a component of nature of science as it entails the process of how scientists carry out their work and how the resultant knowledge is generated. This subscale was made up of five items. Respondents were more likely to choose option 4 (Agree) $(\mathrm{Mdn}=4, \mathrm{IQR}=3)$. Similar to some of the subscales discussed, the length of the boxplot indicates variability in opinion about this component of scientific literacy with more variability among the lower quartile (Figure 1).

The response pattern revealed an interesting trend in the science teachers' beliefs about the nature of science and scientific inquiry. It shows that teachers' beliefs about the tentative nature of science, observations and inferences, and scientific inquiry is quite similar $(\mathrm{Mdn}=4)$. This means teachers' beliefs about these subscales are quite informed because option 4 in the scale represents 'agree'. However, the response pattern for five of the subscales, namely; the scientific method, the subjective method, imaginative and creative method, socio-cultural nature of science and scientific theories and laws, show substantive amount of uncertainty in the teachers' beliefs $(\mathrm{Mdn}=3)$. This suggests that they were not sure whether to agree or disagree with the statements. Furthermore, teachers' beliefs about the empirical nature of science was more confounding because they generally disagreed with this notion $(\mathrm{Mdn}=2)$. It was not possible to ascertain the reasons for this disagreement, whether or not it was a misinterpretation of the items or they simply had different views regarding the empirical nature of science. For this reason, it was imperative to conduct a follow-up interview with participants to get clarity on their responses.

\section{Beliefs Across Gender, Years of Experience and Science Subject Taught}

The assessment of normality of the data was conducted and the Shapiro-Wilk test was significant $(\mathrm{p}<.001)$. This suggests that the data was not normally distributed and non-parametric tests would be appropriate to examine the difference in beliefs (Field, 2009). The Mann-Whitney U test was used to examine the difference in beliefs about nature of science and scientific inquiry based on gender. The results showed that there was no significant difference $(\mathrm{U}=1496, \mathrm{p}=.092)$. It can be concluded that gender does not influence science teachers' beliefs about nature of science and scientific inquiry. Similarly, the Mann-Whitney U test showed no significant difference in beliefs based on the type of science subject (Biology or Physical Science) teachers taught $(\mathrm{U}=1896, \mathrm{p}=.712)$. 
Kruskal-Wallis test was used to examine the difference in beliefs based on ranges of years of science teaching experience. The results once again showed that there was no significant difference in beliefs between the different ranges of years of science teaching experience, $\chi^{2}(3)=6.717, p=.081$, with the mean rank belief score of 83.50 for $0-3$ years, 66.21 for $3-5$ years, 53.33 for 5-10 years, and 66.70 for $10+$ years of science teaching experience. This suggests that teaching experience did not influence teachers' beliefs about nature of science and scientific inquiry.

\section{Conclusion}

This pilot study was carried out in Namibia as part of the initial stages of the validation process in the development of questionnaire for assessing beliefs about nature of science and scientific inquiry. The initial analyses of this instrument indicated that it had potential to be a reliable instrument for assessing beliefs about the nature of scientific knowledge and scientific inquiry in Namibia, with respect to its preliminary very high reliability. This indicates that the items were pulling in one direction in terms of assessing the same construct. However, very high reliability values may indicate unnecessary redundancy of items in the scales. The correlations between subscales that constituted the instrument were generally significantly high. A phenomenon that may indicate that subscales were too similar and therefore the instrument may have poor discriminant validity. This study therefore revealed that science teachers in Namibia have mixed beliefs about the nature of science and scientific inquiry. The study further established that at nonparametric level, gender, science teaching experience, and the type of science subject taught did not influence teachers' beliefs about nature of science and scientific inquiry. Some methodological limitations may have influenced the findings of this study. First, respondents were not interviewed to ascertain accurate interpretation of the questionnaire items or to dig deeper and uncover possible explanations for the variability in their responses (Lederman, AbdEl-Khalick, Bell, \& Schwartz, 2002). It was assumed they interpreted the items as expected. Secondly, it was not possible at this juncture to apply more advanced statistical analyses such as factor analysis to the data due to inadequate sample size.

\section{Acknowledgement}

The author of the paper is on Stipendium Hungaricum Scholarship programme of the Hungarian government in collaboration with the Namibian government through the Namibian Students Financial Assistance Fund (NSFAF). 


\section{References:}

1. Abd-El-Khalick, F., Myers, J. Y., Summers, R., Brunner, J., Waight, N., Wahbeh, N., . . B Belarmino, J. (2017). A logitudinal analysis of the extent and Manner of representations of nature of science in U.S. high school Biology and Physics textbooks. Journal of Research in Science Teaching, 54(1), 82-120.

2. Abd-El-Khalick, F., Waters, M., \& Le, A.-P. (2008). Reprersentation of nature of science in high school chemistry textbooks over the past four decades. Journal of Research in Science Teaching, 45(7), 835855.

3. Carver, R. H., \& Nash, J. G. (2012). Doing data analysis with SPSS version 18. Boston: Brooks/Cole Cengage Learning.

4. Chen, J. A. (2012). Implicit theories, epistemic beliefs, and science motivation: A person-centered approach. Learning and Individual Differences, 22 , 724-735.

5. Chen, J. A., Metcalf, S. J., \& Tutwiler, M. S. (2014). Motivation and beliefs about the nature of scientific knowledge within an immersive virtual ecosystems environment. Contemporary Educational Psychology, 39(2), 112-123.

6. Chen, S. (2006). Development of an instrument to assess views on nature of science and attitudes towards teaching science. Science Education, 90, 803-819.

7. Cohen, L., Manion, L., \& Morrison, K. (2007). Research methods in education (Sixth Ed). New York: Routledge.

8. Conley, A. M. M., Pintrich, P. R., Vekiri, I., \& Harrison, D. (2004). Changes in epistemological beliefs in elementary science students. Contemporary Educational Psychology, 29(2), 186-204.

9. Dagher, Z. R., \& Erduran, S. (2016). Reconceptualizing the nature of science for science education. Science \& Education, 25, 147-164.

10. DeVellis, R. F. (2003). Scale development: Theory and applications (2nd ed.). Thousand Oaks, CA: Sage.

11. Dogan, N., \& Abd-El-Khalick, F. (2008). Turkish grade 10 students' and science teachers'conceptions of nature of science: A national study. Journal of Research in Science Teaching, 45(10), 1083-1112.

12. Elliot, A., \& McGregor, H. A. (2001). A 2 x 2 achievement goal framework. Journal of Personality and Social Psychology, 80(3), 501519.

13. Everitt, B. S. (2002). The Cambridge Dictionary of statistics. Cambridge, UK: Cambridge University Press.

14. Field, A. (2005). Discovering Statistics Using SPSS 2nd Ed. London: Sage. 
15. Field, A. (2009). Discovering Statistics Using SPSS. 3rd Edition. London Sage Publications Ltd.

16. George, D., \& Mallery, P. (2003). SPSS for Windows step by step: A simple guide and reference. 11.0 update (4th ed.). Boston: Allyn \& Bacon.

17. Gliem, J. A., \& Gliem, R. R. (2003). Calculating, Interpreting, and Reporting Cronbach's Alpha Reliability Coefficient for Likert-Type Scales. Science and Education. Columbus, OH, Ohio, USA. Retrieved September 19, 2017, from https://scholarworks.iupui.edu/bitstream/handle/1805/344/

Gliem $+\&+$ Gliem.pdf? sequence $=1$

18. Glynn, S. M., Brickman, P., Armstrong, N., \& Taasoobshirazi, G. (2011). Science motivation questionnaire II: Validation with science majors and nonscience majors. Journal of Research in Science Teaching, 48(10), 1159-1176.

19. Grandy, R., \& Duschl, R. (2008). Consensus: Expanding the scientific method and school science. In R. Duschl, \& R. Grandy, Teaching scientific inquiry: Recommendations for research and implementation (pp. 304-325). Rotterdam, The Netherlands: Sense.

20. Irzik, G., \& Nola, R. (2011). A family resemblance approach to the nature of science for science education. Science \& Education, 20, 591607.

21. Khishfe, R., \& Abd-El-Khalick, F. S. (2002). Influence of explicit and reflective versus implicit inquiry-oriented instruction on sixth graders' views of nature of science. Journal of Research in Science Teaching, 39(7), 551-578.

22. Lederman. (2007). Nature of science: Past, present and future. In S. K. Abell, \& N. G. Lederman, Handbook of research on science education (pp. 831-880). Mahwah, NJ: Lawrence Erlbaum.

23. Lederman, Abd-El-Khalick, F., Bell, R. L., \& Schwartz, R. S. (2002). Views of the nature of science questionnaire: Toward valid and meaningful assessment of learner's conceptions of the nature of science. Journal of Research in Science Teaching, 39(6), 497-521.

24. Lederman, J. S., Lederman, N. G., Bartos, S. A., Bartels, S. L., AntinkMeyer, A., \& Schwartz, R. S. (2014). Meaningful assessment of students' understandings about scientific inquiry-The views about scientific inquiry (VASI) questionnaire. Journal of Research in Science teaching, 51(1), 65-83.

25. Lederman, N. G., \& Abd-El-Khalick, F. (1998). Avoiding De-natured science: Activities that promote understanding of nature of science. In W. F. McComas, The nature of science in science education: 
Rationales and strategies (pp. 83-126). Dordrecht, The Netherlands: Kluwer Academic Publishers.

26. Lederman, N. G., Antink, A., \& Bartos, S. (2014). Nature of science, scientific inquiry and socio-scientific issues arising from genetics: A pathway to developing a scientifically literate citizenry. Science \& Education, 23(2), 285-302.

27. Lederman, J., Lederman, N., Bartels, S., Pavez, J. J., Lavonen, J., Blanquet, E., ... Yalaki, Y. (2017, August 21-25). Understandings of scientific inquiry: An international collaborative investigation of seventh grade students. Paper presented at European Science Education Research Association Conference.https://www.researchgate.net/publication/322603295_un derstandings_of_scientific_inquiry_an_international_collaborative_in vestigation_of_seventh_grade_students

28. Lederman, N. G., Wade, P. D., \& Bell, R. L. (1998). Assessing understanding of nature of science: A historical perspective. In W. F. McComas, The nature of science in science education: Rationales and strategies (pp. 331-350). The Netherlands: Kluwer Academic .

29. Mathews, M. R. (2012). Changing the focus: From nature of science to features of science (FOS). In M. S. Khine, Advances in nature of science research: Concepts and methodology (pp. 3-26). Dordrecht, The Netherlands: Springer.

30. McComas, W. F. (1996). Ten myths of science: Reexamining what we think we know about the nature of science. School Science and Mathematics, 96(1), 10-16.

31. McComas, W. F. (2008). Seeking historical examples to illustrate key aspects of the nature of science. Science \& Education, 17, 249-263.

32. McComas, W. F., Almazroa, H., \& Clough, M. P. (1998). The nature of science in science education: An introduction. Science \& Education, 7, 511-532.

33. Ministry of Education. (2010). National Curriculum for Basic Education. Okahandja: NIED.

34. Niaz, M. (2009). Critical appraisal of physical science as a human enterprise: Dynamics of scientific progress. Dordrecht, The Netherlands: Springer.

35. Nowak, K. H., Tiemann, R., \& Upmeier zu Belzen, A. (2013). Assessing students abilities in processes of scientific inquiry in Biology using a paper-and-pencil test. Journal of Biological Education, 47(3), 182-188.

36. Osborne, J., Collins, S., Ratcliffe, M., \& Duschl, R. (2003). What "ideas-about science" should be taught in school science? A Delphi 
study of the expert community. Journal of Research in Science Teaching, 40(7), 692-720.

37. Peters-Burton, E. (2016). Scientists taking a nature of science course: Beliefs and learning outcomes of career switchers. School Science and Mathematics, 116(3), 148-163.

38. Piedmont, R. L. (2014). Inter-item correlations. In A. C. Michalos, Encyclopedia of Quality of Life and Well-Being Research (pp. 33033304). Netherlands: Springer Netherlands.

39. Schwartz, R. S., Lederman, N. G., \& Crawford, B. A. (2004). Developing views of nature of science in an authentic context: An explicit approach to bridging the gap between nature of science and scientific inquiry. Science Education, 88(4), 610-645.

40. Streiner, D. L. (2003). Starting from the beginning: an introduction to coefficient alpha and internal consistency. Journal of Personality Assessment, 80(1), 99-103.

41. Summers, R., \& Abd-El-Khalick, F. (2017). Development and Validation of an instrument to assess students attitudes towards science across 5 through 10. Journal of Research in Science Teaching, 1-33. doi:10.1002/tea.21416

42. Tsai, C. C., Ho, H. N. J, Liang, J. C., \& Lin, H. M. (2011). Scientific epistemic beliefs, conceptions of learning science and self-efficacy of learning science among high school students. Learning and Instruction, 21(6), 757-769.

43. Vhurumuku, E. (2010). The impact of explicit instruction on undergraduate students' understanding of the nature of science. African Journal of Research in Mathematics, Science and Technology Education, 14(1), 99-111.

44. Wong, S. L., \& Hodson, D. (2009). From the horse's mouth: What scientists say about scientific investigation and scientific knowledge. Science Education, 93, 109-130 